\title{
Reply to comment on: Knol MJ, Twisk JWR, Beekman ATF, Heine RJ, Snoek FJ, Pouwer F (2006) Depression as a risk factor for the onset of type 2 diabetes mellitus. A meta- analysis. Diabetologia 49:837-845
}

\author{
F. Pouwer • M. J. Knol • F. Snoek
}

Received: 17 July 2006 / Accepted: 17 July 2006 / Published online: 14 September 2006

(C) Springer-Verlag 2006

\section{To the Editor:}

Thank you for giving us the opportunity to respond to the stimulating letter of De Jonge and Rosmalen [1]. We agree with our colleagues that the way depression and diabetes are measured could have influenced the results of our meta-analysis, and we have already acknowledged this in our paper [2]. Indeed, the meta-analysis cited on the prevalence of depression in diabetes [3] did show a prevalence of depression of $11.4 \%$ when using psychiatric interview data, vs $31.0 \%$ when using self-report scales. This illustrates that the assessment method can influence results on the prevalence of depression. However, the same review showed that the size of the association between depression and diabetes did not differ as a function of method. Use of a diagnostic interview or a self-report measure yielded similar odds ratios (ORs, 1.9 vs 2.1, respectively, $p=0.5$ ) [3]. We believe that the latter information is more important for our meta-analysis. A meta-analysis by van Melle et al. [4], which studied the association between depression following

F. Pouwer $(\bowtie)$

Department of Medical Psychology,

VU University Medical Center,

Van der Boechorststraat 7,

1081 BT Amsterdam, The Netherlands

e-mail: f.pouwer@vumc.nl

\section{J. Knol}

Julius Center for Health Sciences and Primary Care, University Medical Center,

Utrecht, The Netherlands

F. Snoek

Department of Medical Psychology,

VU University Medical Center,

Amsterdam, The Netherlands myocardial infarction and cardiovascular prognosis, also concluded that the assessment method for depression had no significant effects of assessment method for depression (diagnostic interview $\mathrm{OR}=2.53,95 \%$ CI $1.68-3.80$ vs selfreport $\mathrm{OR}=2.17,95 \% \mathrm{CI} 1.43-3.28$ ). On the other hand, a meta-analysis on depression as a predictor of cardiovascular disease in initially healthy people found a stronger effect size for clinical depression (relative risk $[R R]=2.69,95 \%$ $\mathrm{CI}=1.63-4.43)$ compared with depressive $\operatorname{mood}(\mathrm{RR}=1.49$, 95\% CI 1.16-1.92) [5].

Furthermore, De Jonge and Rosmalen state that the only study in our meta-analysis to look at the effects of formally diagnosed depression on type 2 diabetes incidence did not find a significantly raised risk. In our opinion, looking at statistical significance alone is not justified in this case. The size of both the association and the study sample are also important. The relative risk of 2.23 was still one of the highest relative risks in our meta-analysis [6]. It should also be noted that the 95\% CI (0.90-5.55) approached statistical significance even though the study sample was relatively small.

The authors also state that 'the presence of diabetes is nothing more than the crossing of a more-or-less arbitrary cut-off value for insulin resistance'. We agree that the diagnosis of type 2 diabetes is based on arbitrary cut-off values. However, increased glucose levels in type 2 diabetes are not simply a function of insulin resistance, but beta cell dysfunction as well. More important is the fact that the aim of the studies included in our metaanalysis was not to study whether depression is associated with increased levels of insulin resistance or impaired glucose metabolism but whether depression increases the risk of developing type 2 diabetes. 
Furthermore, we hold the opinion that De Jonge and Rosmalen use inconsistent reasoning in their letter, as the same principle holds true for the measurement of depression. The diagnosis of major depression is also defined by an arbitrary border. One could argue that depression is not a simple yes/no phenomenon, but rather a continuum of negative affect.

Finally, we do not agree with the following statement: 'The question, "Can we prevent diabetes by treating depression?" can only be answered using diagnostic data on depression, and the aetiological question, "Can depression cause diabetes?" can only be addressed using blood glucose levels.' We think that these questions are in essence the same. If treating depression can indeed prevent diabetes, we can also answer the aetiological question of whether depression causes diabetes.

All nine studies included in our meta-analysis can be regarded as opportunistic studies, i.e. they were probably not designed to test the association between depression and onset of type 2 diabetes. As a consequence, less than optimal measurement methods were used. We therefore fully agree with De Jonge and Rosmalen's plea that new, well-designed studies are urgently needed in this area.

\section{References}

1. De Jonge P, Rosmalen JGM (1996) Comment on: Knol MJ, Twisk JWR, Beekman ATF, Heine RJ, Snoek FJ, Pouwer F (1996) Depression as a risk factor for the onset of type 2 diabetes mellitus. A meta-analysis. Diabetologia 49:837-845 DOI 10.1007/s00125-006-0389y

2. Knol MJ, Twisk JWR, Beekman ATF, Heine RJ, Snoek FJ, Pouwer F (2006) Depression as a risk factor for the onset of type 2 diabetes mellitus. A meta-analysis. Diabetologia 49:837-845

3. Anderson RJ, Freedland KE, Clouse RE, Lustman PJ (2001) The prevalence of comorbid depression in adults with diabetes: a metaanalysis. Diabetes Care 24:1069-1078

4. van Melle, JP, de Jonge P, Spijkerman TA et al (2004) Prognostic association of depression following myocardial infarction with mortality and cardiovascular events: a meta-analysis. Psychosom Med 66:814-822

5. Regulies R (2002) Depression as a predictor for coronary heart disease. A review and meta-analysis. Am J Prev Med 23:51-56

6. Eaton WW, Armenian H, Gallo J, Pratt L, Ford DE (1996) Depression and risk for onset of type II diabetes. A prospective population-based study. Diabetes Care 19:1097-1102 